\title{
TULBURARE DE MIGRARE NEURONALĂ - CAZ CLINIC
}

\author{
Dr. Carmen Voicilă, Dr. Anca Cabat, Dr. Raluca Gabriela Ioan \\ Institutul de Ocrotire a Mamei şi Copilului ,,Alfred Rusescu“, Bucureşti
}

\begin{abstract}
REZUMAT
Autorii prezintă cazul unui nou-născut transferat la 43 h de la naştere în Clinica de Neonatologie IOMC Polizu pentru sindrom de detresă respiratorie neonatală şi suspiciune de infecție materno-fetală, care a fost investigat extensiv pe parcursul internării pentru persistența tulburărilor de tonus muscular neexplicate printr-o asfixie la naştere, fiind diagnosticat în urma examenului RMN cu heterotopie periventriculară dreaptă asociată cu chist porencefalic temporal stâng şi schizencefalie de aceeaşi parte.
\end{abstract}

Cuvinte cheie: heterotopie corticală, RMN, hipotonie de cauză centrală

\section{INTRODUCERE}

Migrarea neuronală reprezintă procesul prin care celulele nervoase se deplasează de la locul formării lor - zonele germinative ventriculare şi periventriculare - la sediul definitiv din SNC unde vor rămâne pe parcursul întregii vieți. Plasarea lor în diferite straturi ale cortexului este determinată genetic. În prezent sunt descrise două tipuri de migrare neuronală: radială şi tangenţială.

Alterarea procesului normal de migrare (L3-L5 de sarcină) şi organizare neuronală corticală (L5 perioada neonatală) duce la apariția de malformații structurale cerebrale grupate sub denumirea de tulburări de migrare neuronală.

Acestea au fost grupate folosind criterii clinice, neuroimagistice şi caracteristici genetice în:

- Lisencefalie - complexul agirie/pahigirie: absența/dezvoltarea parţială a girilor şi a santurilor la nivel cortical (aspect de ,creier neted"/girusuri late, scăzute ca număr). Histologic, se împarte în tipul I (tipul clasic Bielschowski) şi tipul II (sindromul WalkerWarburg). Clinic, există encefalopatie cu hipotonie axială severă. Decesul survine în primele luni de viață.
- Polimicrogirie: număr mare de plicaturi mici la nivelul scoarței. Cel mai frecvent apare în teritoriul arterei cerebrale mijlocii.

- Schizencefalie: discontinuitate de substanță cenuşie întinsă pe lungimea unui întreg emisfer, la nivelul santului central Rolando sau a scizurii Sylvius

- Heterotopii neuronale: grupuri de neuroni normali care nu au migrat (periventriculară) sau care s-au oprit din migrarea către cortex (subcorticală). Mecanismul este insuficient cunoscut, cel mai probabil fiind vorba despre o tulburare în apoptoză (mecanismul de moarte celulară), programat genetic. Se consideră a fi implicate în etiopatogenia epilepsiilor.

- Disgenezii corticale/displazii corticale focale: arii corticale cu structură dezorganizată. Clinic, tabloul este dominat de epilepsii focale şi semne de deficit neurologic.

Etiologia acestor malformații nu este pe deplin precizată putând fi implicați atât factori genetici (defecte structurale ale moleculelor care condiționează migrarea neuronală), cât şi factori vasculari, toxici, metabolici sau infecțioşi (ca de exemplu infecția CMV în L3-4 de sarcină). 
Defectele de migrare neuronală stau la baza a numeroase tulburări de dezvoltare psihomotorie şi se estimează că aprox. 40\% dintre copiii cu epilepsie rezistentă la tratament prezintă o astfel de anomalie cerebrală. Simptomatologia mai include: hipotonie axială, retard mintal, falimentul creşterii, dificultăți de alimentație, limfedem, microcefalie, disfuncție motorie. De regulă, aceşti copii au fenotip normal.

Majoritatea acestor malformații sunt diagnosticabile prin examen RMN. Se pot completa investigațiile cu EEG pentru monitorizarea convulsiilor şi EMG pentru evaluarea tonusului muscular.

Tratamentul este de cele mai multe ori simptomatic şi suportiv - fiziokinetoterapie, terapie ocupațională, logopedie, medicație anticonvulsivantă, cura chirurgicală pentru epilepsiile rezistente la tratament fiind rezervată cazurilor selecționate.

Prognosticul pacienților cu sindrom de migrare neuronală anormală este variabil şi depinde de aria corticală afectată, tipul leziunii şi gradul deficitului neurologic. Poate exista afectare neurologică minoră sau, în alte cazuri, afectare extrem de gravă, mergând până la măsuri de terapie intensivă pentru susținerea funcțiilor vitale. Sindromul se poate asocia şi cu alte anomalii congenitale, apărând complicații ce agravează prognosticul.

\section{CAZ CLINIC}

Nume: M.L.G.

Sex: masculin

Data naşterii: 22.03 .2014 , ora $16: 30$

VG: 38 săptămâni

GN: $3300 \mathrm{~g}$ T: $50 \mathrm{~cm}$ PC: nu avem date IP 2,64 (armonic)

AHC

Mama: 25 ani, IIIG, IP (un avort spontan trim I, cauză neprecizată, şi un avort la cerere), vânzătoare, fără expunere la mediu toxic, afirmativ sănătoasă, fumătoare (inclusiv pe durata sarcinii), grup AII Rh pozitiv.

Tatăl: afirmativ sănătos, grup AII Rh pozitiv

Ambii neagă antecedente familiale de epilepsie sau alte boli neurologice, precum şi consangvinitatea.

\section{Sarcina}

UM: 27.06.2013, LE: prima lună, PMF: 3 luni, dispensarizată la medicul ginecolog, ecografii efectuate lunar, inclusiv morfologie fetala (toate în limite normale), screening TORCH efectuat - fără infecții acute, infecție de tract urinar cu E. Coli în trimestrul II, tratată cu Augmentin po, culturi control afirmativ negative, fără altă medicație pe parcursul sarcinii.

\section{Naşterea}

Prin operație cezariană, din prezentație craniană, SA 8. A fost intubat la câteva ore de la naştere pentru SDR cu agravare progresivă şi a primit surfactant, precum şi tratament antibiotic parenteral. Paraclinic: procalcitonină cu valoare crescută. A fost transferat în Clinica IOMC Polizu la $43 \mathrm{~h}$ de viață.

\section{Examen clinic la internare}

Nou-născut normopoderal, stare generală gravă, tegumente rozate $\mathrm{cu}$ icter moderat, edeme generalizate, FA normotensivă, zgomote cardiace ritmice la stânga sternului, AV 150 bpm, Tam 30 $\mathrm{mmHg}$, IOT/VM, MV simetric, ronhusuri bilateral, $\mathrm{SpO} 2$ 96\% (FiO2 40\%), respirații spontane prezente, abdomen suplu, vezică urinară palpabilă, tonus şi reactivitate scăzute - sedat.

\section{Diagnostic anamnestico-clinic:}

Insuficiență cardiocirculatorie acută. SDR insuficiență respiratorie acută.

\section{Examene paraclinice la internare:}

Hemogramă: Hb 14 g/dl, Ht 42,6\%, 18020 le/ $\mathrm{mmc}, 358000 \mathrm{trb} / \mathrm{mmc}$; Biochimie: glicemie 104 $\mathrm{mg} / \mathrm{dl}$, ALT $41 \mathrm{U} / \mathrm{L}$, crea $1,3 \mathrm{mg} / \mathrm{dl}$, uree $37 \mathrm{mg} / \mathrm{dl}$, Ca 7,2 mg/dl, CRP 0,8, BiT 8,46 mg/dl, BiD 0,22 $\mathrm{mg} / \mathrm{dl}, \mathrm{Cl} 98 \mathrm{mmol} / \mathrm{L}, \mathrm{K}$ 4,4 mmol/L, Na 132 $\mathrm{mmol} / \mathrm{L}$. Culturi periferice şi centrale negative. ETF: VLS cu aspect de „fulgi de zăpadă“. Chist subependimar stâng. Hiperecogenitate biparietală la nivelul scizurii Sylvius.

\section{Evoluție şi tratament:}

Nou-născut admis în TINN, ventilat mecanic, cu tratament antibiotic parenteral (Meronem şi Vancomicină), suport inotrop (Dopamină şi Dobutamină), nutriție parenterală totală, cateterizare vezică urinară, monitorizare funcții vitale, TA, diureză. Evoluția a fost lent favorabilă, cu înlăturarea suportului ventilator după 6 zile, suprimarea pev cu Dopamină şi Dobutamină după 3 zile şi a sedării cu Dormicum iv după 6 zile.

Evoluția neurologică se menține nesatisfăcătoare, cu hipotonie şi hiporeactivitate în lipsa tratamentului sedativ, cu dificultate în inițierea alimentației la biberon (reflex de supt mult diminuat). ETF de control reafirmă prezența hiperecogenităților la nivelul scizurii Sylvius. Se decide efectuarea RMN cerebral nativ, care concluzionează: heterotopie subcorticală cu aspect curbiliniu, la nivelul peretelui intern al cornului posterior al ventriculului drept. Chist arahnoidian de pol anterior temporal stâng.

În acest context se efectuează consult neurologic, care evidențiază: „Sindrom hipoton central moderat. Modificări de grupă multiple: chist porencefalic temporal stg asociat $\mathrm{cu}$ schizencefalie de 
aceeaşi parte. Heterotopie inter şi periventricular VLD“. Se recomandă monitorizare neurologică periodică.

Nou-născutul a fost externat la domiciliu la 22 de zile de la internare, cu stare generală bună, echilibrat cardiorespirator, digestiv, renal, cu reactivitate uşor diminuată şi hipotonie axială moderată. De precizat că pe durata spitalizării nu a prezentat episoade convulsive.

\section{Particularitatea cazului:}

Stabilirea diagnosticului de malformație cerebrală la vârsta de nou-născut, de regulă confirmarea RMN a unei asemenea tulburări făcându-se în jurul vârstei de 1 an, când se definitivează tabloul clinic/ neurologic.

Lipsa factorilor de risc: părinți tineri, fără consagvinitate, fără expunere la teratogene ambientale, fără infecții din spectrul TORCH în sarcină, fără istoric familial de epilepsie sau alte boli neurologice.

Malformație cerebrală complexă - asociere de heterotopie neuronală periventriculară cu schizencefalie şi chist porencefalic.

Lipsa manifestărilor de tip convulsiv pe durata internării, în contextul coexistenței tulburărilor metabolice, electrolitice şi instabilităţii circulatorii. 